\title{
Comparison of internal diameter of great arteries in congenital heart disease A cross-sectional echocardiographic study
}

\author{
W J GUSSENHOVEN, B F VAN LEENEN, W KUIS, V H DE VILLENEUVE, N BOM, \\ H VAN MEURS-VAN WOEZIK
}

From the Interuniversity Cardiology Institute, Thoraxcenter and Sophia Children's Hospital, Rotterdam, The Netherlands

SUMMARY Cross-sectional echocardiographic studies were used to measure and compare the internal diameter of both aortic root and pulmonary artery in 104 patients with normally related great arteries. Six groups of patients were assessed: normal, with an intracardiac shunt, with tetralogy of Fallot, with pulmonary stenosis, with aortic stenosis, and with atresia of the right atrioventricular valve orifice.

In addition, a postmortem study was carried out in normal heart specimens and in specimens with an atrioventricular septal defect. It appeared that the echocardiographically studied ratio between the aortic and pulmonary artery diameter varied considerably. In normal subjects the pulmonary artery diameter tends to be slightly larger than the aortic root diameter: this observation was confirmed by the postmortem data. In other instances the pulmonary artery diameter appeared to be smaller than the aortic root diameter, for example patients with tetralogy of Fallot and those with tricuspid atresia, whereas the reverse was noted in patients with an intracardiac shunt. This two dimensional study has shown that functional adaptations of the calibre of the great arteries can be measured and identified in patients with congenital heart disease.

At necropsy the pulmonary orifice of the normal heart is slightly larger than that of the aorta. ${ }^{2}$ In certain forms of congenital heart disease, however, the diameters of the orifices are known to change with

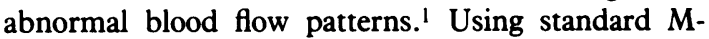
mode echocardiography, it may be possible to determine the diameter of the pulmonary artery. ${ }^{3}$ The ability, however, to establish precisely the dimension of the pulmonary artery in various forms of congenital heart defects is limited, since one cannot be sure of visualising this structure perpendicular to its axis. ${ }^{4}$ The spatial orientation provided by cross-sectional echocardiography should permit more detailed characterisation of the diameter of the aorta and the pulmonary artery. Attempts, echocardiographically, to characterise changes in luminal diameter at the different sites within the aortic root have been successful both in normal subjects and in patients with supravalvular aortic stenosis. ${ }^{5}$

This report describes our experience using a two dimensional real time technique in establishing the aorta and pulmonary artery internal diameter in normal

Accepted for publication 20 July 1982 individuals and in a variety of patients with a congenital heart disease, but with normally related great arteries. For correlation purposes a postmortem study was carried out in subjects with normal hearts as well as in patients with an atrioventricular septal defect.

\section{Subjects and methods}

The material for this study consisted of 104 patients, from newborn up to 18 years (average $9 \cdot 1$ years). There were 48 boys and 56 girls. All patients had situs solitus atria, concordant atrioventricular connection, and concordant ventriculoarterial connection. ${ }^{6}$ Patients with pulmonary atresia or truncus arteriosus were excluded. Standard cardiac catheterisation and cineangiography were performed in 90 patients.

The two dimensional real time investigation was conducted with a dynamically focused linear array system, which has a frequency of $3 \cdot 1 \mathrm{MHz} .{ }^{7}$ Both left and right parasternal ventricular long axis views have been studied in order to measure the internal diameters of both the aorta and pulmonary artery.

The patients were divided into six groups: 
(1) Normal children (14).

(2) Patients with an intracardiac shunt (31): (A) secundum type atrial septal defect (11), (B) perimembranous ventricular septal defect (seven), and (C) atrioventricular septal defect (13).

(3) Tetralogy of Fallot (14): (A) preoperative (seven) and (B) postoperative total correction (seven).

(4) Pulmonary stenosis (16).

(5) Aortic stenosis (11).

(6) Atresia of the right atrioventricular orifice (tricuspid atresia) (18): (A) pre-Fontan operation (13) and (B) post-Fontan operation (five).

When proven haemodynamically, the severity of the pulmonary stenosis (group 4) was mild in four, moderate in eight, and severe in two patients, while the severity of the aortic stenosis (group 5) was mild in six and moderate in three patients.

The seven patients from group 3B (postoperative tetralogy of Fallot) had undergone a total surgical correction. The ventricular septal defect was closed. A pericardial patch was used to increase the right ventricular outflow tract and main pulmonary artery in four patients, while in two patients only the outflow tract was increased. In the remaining patient a resection of the muscular obstruction of the right ventricular outflow was carried out. Five patients in group 6 (group 6B) underwent a Fontan's correction. The right atrium was directly connected to the outflow chamber using a conduit.

The left ventricular long axis view was studied in 103 patients, and the right ventricular long axis view in 90 patients. In 89 patients both left and right ventricular long axis views were studied. In each patient four middiastolic still frames were selected at the largest diameter of the great artery. Care was taken to ensure that the measurements recorded were at the mid-point of the lumen of both great arteries. Mid-diastolic frames were selected, since it appeared that the sinuses of Valsalva were thus best visualised. With computer analysis, measurements were taken from the inner surface of the anterior vessel echo to the inner surface of the posterior vessel echo at each level..$^{5}$ The internal diameter of the aortic root was measured at (1) aortic annulus, (2) sinuses of Valsalva, and (3) the aorta distal to the sinuses of Valsalva. The internal diameter of the pulmonary artery was measured at (1) the level proximal to the pulmonary valve, (2) the pulmonary valve, and (3) the pulmonary artery $1 \mathrm{~cm}$ distal to the valve (Fig. 1).

For each patient the mean and the variance of the measurements of the internal diameter in the ascending aorta and pulmonary artery were calculated from the selected still frames. In order to determine the most reliable location at which to measure the diameter of the great arteries, the variances were pooled according to the fomula ${ }^{8}$ :

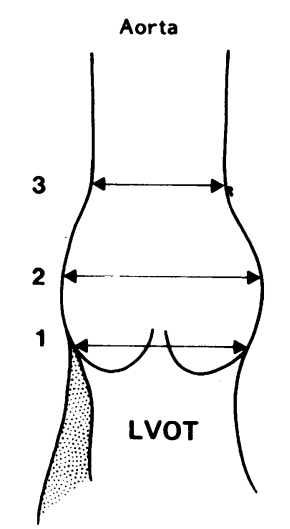

parasternal left ventricular long axis view
Pulmonary artery

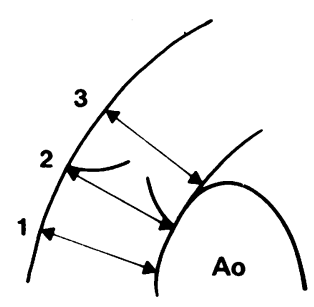

parasternal right ventricular long axis view
Fig. 1 Sites of measurements used to determine the aortic (Ao) root diameter are, respectively (1) aortic annulus, (2) sinuses of Valsalva, and (3) the aorta internal diameter distal to the sinuses of Valsalva. The sites of measurements used to determine the pulmonary artery diameter are (I) the level proximal to the pulmonary valve, (2) pulmonary valve, and (3) the area distal to the pulmonary valve. LVOT, left ventricular outflow tract.

$\operatorname{VAR}_{\text {pooled }}=\frac{\sum n_{i} \operatorname{var}_{i}}{\sum\left(n_{i}-1\right)}$

with $n_{i}=$ number of measurements for patient $i$ $\operatorname{var}_{i}=$ variance of patient $i$

It has been suggested by Van Meurs-van Woezik ${ }^{9}$ that a variable such as the squared diameter of the semilunar valve orifices may be used as an indicator of blood flow through the arteries, and that when expressed as a percentage of the sum total of the squared values this variable becomes independent of the patient's weight, age, and size.

In this study we have calculated the ratio of the squared aortic and pulmonary artery internal diameter, obtained at valvular level, as the ratio of aorta to pulmonary artery.

The size of a great artery should be measured from the leading edge of the anterior wall of the great artery to the leading edge of the posterior wall of the great artery. Using the two dimensional technique, however, this rule could not be applied reliably in both the aortic and pulmonary artery. Since we have specifically examined the ratio between the great arteries, the influence of this error on the measurements will be limited.

Finally a postmortem study was carried out in 17 normal heart specimens (age range 0 to 9 years; average 3 years) as well as in 17 heart specimens with an atrioventricular septal defect, either with a complete or an 
incomplete form of this disease (age range 0 to 6.5 years; average 1 year).

Internal diameters of aortic and pulmonary ostium were measured with the aid of calibrated probes differing one millimetre in diameter. The data have been expressed as the ratio of aorta to pulmonary artery.

\section{Results}

The quantitative data obtained from the selected still frames, at each measured site within the aortic root and pulmonary artery, showed in both a minimum variance at valvular level (Table 1; aortic root: level 1; pulmonary artery: level 2 ). The results of the squared diameter measurements of both the aortic and pulmonary artery orifices, obtained at valvular level, in the 89 patients in whom both left and right parasternal long axis views were available, are shown in Table 2.

In the ascending aorta the diameter at the annular level (level 1) corresponds to the diameter at the level

Table 1 Pooled variance of measurements for each measured site summarised over all 103 patients studied with left ventricular parasternal long axis view and 90 patients studied with right ventricular parasternal long axis view: mesurement obtained at both aortic (level 1) and pulmonary valvular level (level 2) showed minimum variability

\begin{tabular}{lllllll}
\hline & Aorta & & \multicolumn{4}{c}{ Pulmonary artery } \\
\hline $\begin{array}{l}\text { Measured site } \\
\begin{array}{l}\text { Pooled variance of } \\
\text { measurements }\left(\mathrm{mm}^{2}\right)\end{array}\end{array}$ & 1 & 2 & 3 & 1 & 2 & 3 \\
\hline
\end{tabular}

distal to the sinuses of Valsalva (level 3), though the latter diameter tends to be slightly greater than that recorded at the aortic annulus. The diameter determined at the level of the sinuses of Valsalva (level 2) showed an increase in comparison to the measurements obtained at the annular level (level 1).

Within the pulmonary artery the diameter decreases slightly from proximal to distal levels (1 up to 3); except in patients with tetralogy of Fallot (group 3A: preoperative) and in patients with valvular pulmonary stenosis, an increased diameter was noticed in the area distal to the pulmonary valve (level 3 ). The internal diameters obtained postmortem at valvular level within the aortic root and pulmonary artery in normal specimens and in specimens with an atrioventricular septal defect are shown in Table 3, together with the echocardiographic data obtained in the similar groups.

\section{Discussion}

It has been shown that the calibres of the aorta and pulmonary trunk and of the ostia of the heart, both normally and in conditions of alteration of blood flow, are directly related to the functional load on that vessel and ostium. ${ }^{110}$ Van Meurs-van Woezik ${ }^{9}$ reported that in 53 normal specimens the relative cross-sectional area of the pulmonary ostia tended to be larger than the aortic ostia (Ao/PA ratio 1:1·29). Moreover, she noted that the ascending aorta and pulmonary trunk were slightly larger in diameter than the aortic and pulmonary ostia, respectively (both approximately $9 \%$ larger). De la Cruz et al. ${ }^{2}$ documented a squared aortic versus pulmonary artery orifice ratio, with a mean

Table 2 Ratio of squared aortic $(A o)$ and pulmonary artery $(P A)$ diameter, obtained at valvular level, calculated in 89 patients: in each group mean squared value of group is calculated

\begin{tabular}{|c|c|c|c|c|}
\hline \multirow[t]{2}{*}{ Diagnosis } & & \multicolumn{2}{|l|}{ Mean } & \multirow{2}{*}{$\begin{array}{l}\text { No. of } \\
\text { patients }\end{array}$} \\
\hline & & $A o^{2}: P A^{2}$ & $S D$ & \\
\hline Group 1 & Normal & $1: 1 \cdot 35$ & $0 \cdot 32$ & $9(14)$ \\
\hline $\begin{array}{r}\text { Group } 2 \\
2 \mathrm{~A} \\
2 \mathrm{~B} \\
2 \mathrm{C}\end{array}$ & $\begin{array}{l}\text { Intracardiac shunt } \\
\text { ASD } \\
\text { VSD } \\
\text { AVS defect }\end{array}$ & $\begin{array}{l}1: 1 \cdot 79 \\
1: 2 \cdot 51 \\
1: 1.40 \\
1: 1 \cdot 79\end{array}$ & $\begin{array}{l}1.00 \\
0.65 \\
0.49\end{array}$ & $\begin{array}{l}25(31) \\
10 \\
5 \\
10\end{array}$ \\
\hline $\begin{array}{r}\text { Group } 3 \\
3 \mathrm{~A} \\
3 \mathrm{~B}\end{array}$ & $\begin{array}{c}\text { Tetralogy of Fallot } \\
\text { Preoperative } \\
\text { Postoperative }\end{array}$ & $\begin{array}{l}1: 0.88 \\
1: 1.37\end{array}$ & $\begin{array}{l}0.35 \\
0.42\end{array}$ & $\begin{array}{l}14(14) \\
7 \\
7\end{array}$ \\
\hline Group 4 & Pulmonary stenosis & $1: 1 \cdot 35$ & $0 \cdot 26$ & $14(16)$ \\
\hline Group 5 & Aortic stenosis & $1: 1 \cdot 29$ & $0 \cdot 38$ & $9(11)$ \\
\hline $\begin{array}{r}\text { Group } 6 \\
6 \mathrm{~A} \\
6 \mathrm{~B}\end{array}$ & $\begin{array}{l}\text { Tricuspid atresia } \\
\text { Before Fontan } \\
\text { After Fontan }\end{array}$ & $\begin{array}{l}1: 0.36 \\
1: 0.73\end{array}$ & $\begin{array}{l}0.23 \\
0.31\end{array}$ & $\begin{array}{l}18(18) \\
13 \\
5\end{array}$ \\
\hline
\end{tabular}

SD, standard deviation; ASD, secundum type atrial septal defect; VSD, perimembranous ventricular septal defect; AVS defect, atrioventricular septal defect. Note that "No. of patients" represents the number of patients in whom both right and left ventricular long axis view were available, while those between brackets represent the original group. 
Table 3 Comparison between echocardiographic and postmortem study of ratio of squared aortic $(A o)$ and pulmonary artery (PA) diameter obtained at valvular level, calculated in normal subjects as well as in those with atrioventricular septal defect

\begin{tabular}{|c|c|c|c|c|}
\hline & \multicolumn{2}{|l|}{ Echo } & \multicolumn{2}{|l|}{ Necropsy } \\
\hline & \multicolumn{2}{|l|}{ Mean } & \multicolumn{2}{|l|}{ Mean } \\
\hline & $A o^{2}: P A^{2}$ & $S D$ & $A o^{2}: P A^{2}$ & $S D$ \\
\hline \multirow{2}{*}{$\begin{array}{l}\text { Normal } \\
\text { Atrioventricular septal } \\
\text { defect }\end{array}$} & $1: 1 \cdot 35$ & 0.32 & $1: 1 \cdot 39$ & $0 \cdot 30$ \\
\hline & $1: 1 \cdot 79$ & 0.49 & $1: 1 \cdot 70$ & 0.41 \\
\hline
\end{tabular}

value of $1: 1 \cdot 16$. They found no distinct relation between the patient's age and this ratio.

The postmortem data of the pulmonary and aortic ostium correspond with those obtained in vivo using M-mode echocardiography, when the measurements were made through the centre of the ostium. ${ }^{13}{ }^{11}$ Using $M$-mode echocardiography the aortic root and pulmonary artery were measured between the outside echoes of the anterior and posterior wall. ${ }^{311}$ Solinger $e t$ $a l .{ }^{3}$ have taken the measurements in end-systole, while Epstein $e t a l .{ }^{4}$ and Goldberg et al. ${ }^{11}$ used end-diastole. Measurements from the pulmonary artery using Mmode echocardiography are difficult to obtain. ${ }^{+}$In

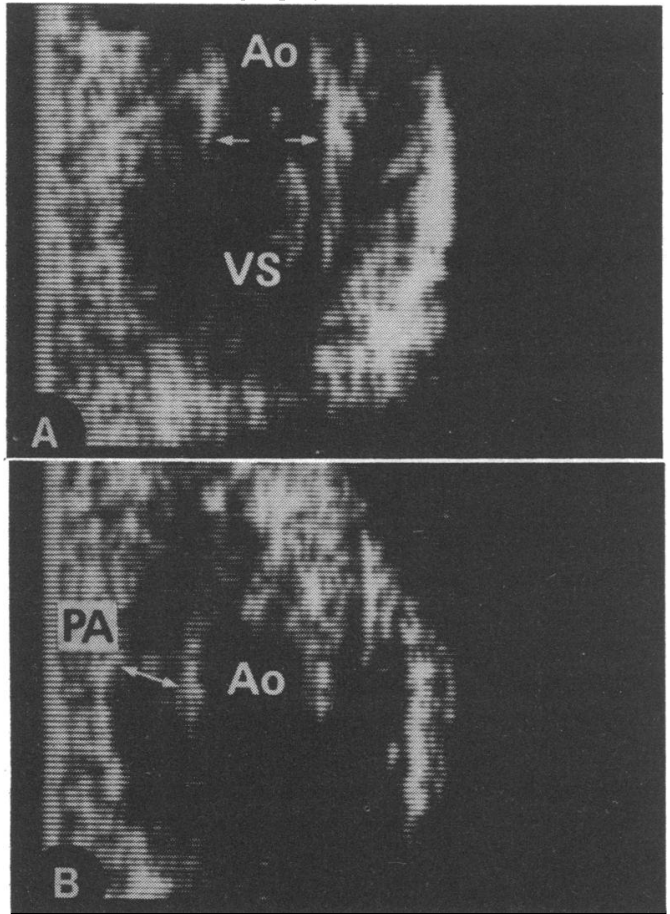

Fig. 2 Two dimensional left $(A)$ and right $(B)$ parasternal long axis view in a patient with tetralogy of Fallot (group $3 A)$. (A) The aorta $(A o)$ which overrides the ventricular septum $(V S)$. The internal diameter of the aortic root is obviously larger than the pulmonary artery $(P A)$ internal diameter $(B)$.

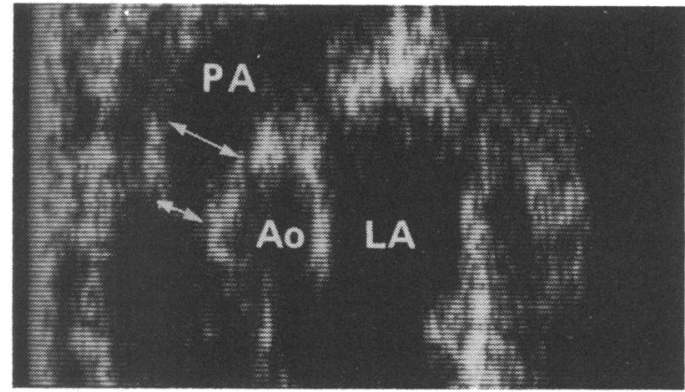

Fig. 3 Two dimensional right parasternal long axis view obtained in a patient with severe pulmonary valve stenosis (gradient $115 \mathrm{mmHg}$ ) showing post-stenotic dilatation (compare arrows). Ao, aorta; LA, left atrium; PA, pulmonary artery.

addition, comparable necropsy to $M$-mode echocardiographic data from a suprasternal position from the ascending aorta have been reported. ${ }^{12} 13$

With the introduction of two dimensional echocardiographic systems, it became possible to assess, even more accurately, the diameter of both great arteries. As has been pointed out by Weyman et al., ${ }^{5}$ the true diameter of a tubular vessel can only be obtained when the sound beam is perpendicular to the walls of the vessel and traverses the lumen at its mid-portion. They obtained the measurements from the inner aspect and at various sites of the aortic root. It appeared that the measurements obtained in 20 normal subjects at valvular level of the aortic root showed a minimum variability. These observations are in agreement with those obtained in our study (see Table 1). In addition, the diameter above the sinuses of Valsalva turned out to be similar to or slightly larger than that recorded at the aortic annulus.

Furthermore, confirmation was found of the statement that the calibres of the ostia of the pulmonary trunk and the aorta are directly related to the functional load on the vessel and ostium. ${ }^{1}$ In the normal subjects (group 1) the squared diameter of the pulmonary ostium tends to be larger than that of the aortic ostium (Ao/PA ratio 1:1.35). In patients with an intracardiac shunt, with an increased flow through the right ventricle and the pulmonary artery, an increased ratio with a slightly larger pulmonary trunk was detected. In particular, the patients with an atrial septal defect (Ao/ PA ratio $1: 2.51)$ and those with an atrioventricular septal defect (Ao/PA ratio $1: 1 \cdot 79$ ) were shown to have increased pulmonary diameter.

In contrast, the patients with a ventricular septal defect showed a ratio comparable to the normal value (Ao/PA ratio 1:1.40). Among these were three patients in whom no clinical evidence for a large defect was present. In two patients cardiac catheterisation was performed and the size of the shunt measured with the Fick method (QP:QS) was 1·3:1 and 2:1, respectively, 

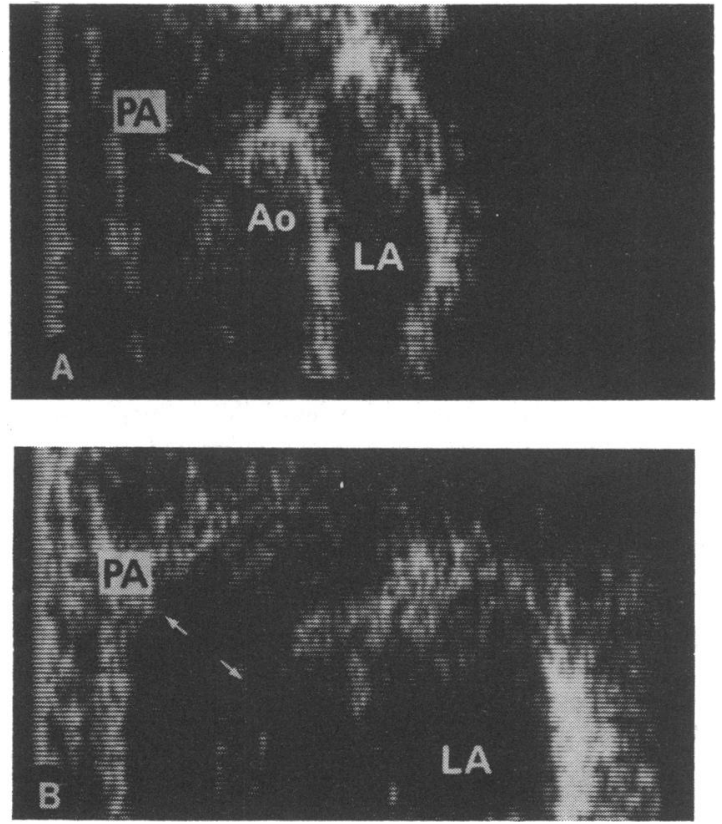

Fig. 4 Two dimensional right parasternal long axis view obtained in patients with absent right atrioventricular valve orifice (groups $6 A$ and $B)$. (A) The pulmonary artery $(P A)$ internal diameter seen before operation; $(B)$ after the Fontan procedure. Note that the diameter of the pulmonary artery has increased considerably after operation. Ao, aorta; $L A$, left atrium.

with no increased pulmonary pressure. We observed that in other cases (not included in this study), in which a ventricular septal defect was complicated by pulmonary hypertension, the pulmonary artery did increase in size. This phenomenon may probably be explained by the increased pulmonary resistance.

The third group of patients had tetralogy of Fallot. Because of the intrinsic abnormality common to this condition, an increased aortic root in comparison to the pulmonary artery diameter was noticed (Ao/PA ratio 1:0.88) (Fig. 2). Patients operated on for a tetralogy of Fallot showed, after operation, an increased pulmonary artery diameter (Ao/PA ratio $1: 1.37$ ) It is noteworthy that we have investigated two patients with an aneurysm-like dilatation of the pulmonary artery and right ventricular outflow tract. Both patients, not included in this study, underwent a total correction for a tetralogy of Fallot in which the pericardial outflow patch extends on to the main pulmonary artery.

In patients with pulmonary stenosis the normal difference between aorta and pulmonary artery was undisturbed (Ao/PA ratio $1: 1 \cdot 35$ ), as was the ratio found in patients with an aortic stenosis (Ao/PA ratio $1: 1 \cdot 29)$. In addition, poststenotic dilatation was measurable in patients with pulmonary valve stenosis (Fig. 3), but not in those with an aortic valve stenosis. The explanation for the absence of poststenotic dilatation in the latter group of patients might be that the degree of obstruction found haemodynamically was generally mild. Patients with a classical tricuspid atresia (group 6) showed an extremely reduced diameter of the pulmonary artery (Ao/PA ratio $1: 0 \cdot 36$ ) (Fig. 4A). This, we assume, directly corresponds with the reduced blood flow across the pulmonary artery. The postoperative data (Fontan) disclosed a 50\% increase in diameter of the pulmonary artery. The ratio of aorta to pulmonary artery was 1:0.73 (Fig. 4B).

In addition, we compared our echocardiographic data on the ratio of the aorta to the pulmonary artery with the postmortem data in normal subjects as well as in those known to have an atrioventricular septal defect. It was found that the necropsy data corresponded with the echocardiographic data in vivo (Table 3 ).

Finally, taking into account the large standard deviation as seen in Table 2, it should be realised that this could be decreased by selecting a comparable group of patients, all of them, for instance, with the same degree of shunt.

\section{Conclusion}

Using the two dimensional parasternal long axis view, it is possible to determine the internal diameter of the great arteries at various locations. It appears that the measurements obtained at valvular level, both at the aortic annulus and pulmonary valve annulus, show least variability.

Since the internal diameters differ so much with age, the squared values of the internal diameter, which indicate the cross-sectional areas, were expressed as a percentage of the sum total of the squared internal diameters of the aortic and pulmonary ostia in all 89 patients in whom both left and right parasternal long axis views were available.

In normal hearts the diameter of the pulmonary artery is shown to be slightly larger than that of the aorta. In congenital heart disease, an obvious change from the normal values of the cross-sectional areas was found at the ostia of either the pulmonary artery or the aorta. The pulmonary artery diameter was increased in comparison with the aortic root diameter in patients with an intracardiac shunt (except in ventricular septal defects). The pulmonary artery diameter was decreased in comparison with the aortic root diameter in cases of tetralogy of Fallot (preoperative) and tricuspid atresia. Accordingly, changes were seen before and after operation in the aorta to pulmonary artery ratio. All these observations indicate that quantitative data of the calibres of the aortic and pulmonary ostia are influenced by pathological 
conditions and change after surgery.

Postmortem observations were in agreement with the echocardiographic data.

We are indebted to Professor E Bos for the surgical data. We thank Mr H Rijsterborgh and Dr J Lubsen for their statistical advice.

\section{References}

1 Van Meurs-van Woezik H, Klein HW, Krediet P. Normal internal calibres of ostia of great arteries and of aortic isthmus in infants and children. Br Heart $\mathcal{F}$ 1977; 39: $860-5$.

2 De la Cruz MV, Anselmi G, Romero A, Monroy G. A qualitative and quantitative study of the ventricles and great vessels of normal children. Am Heart $\mathcal{J}$ 1960; 60: 675-90.

3 Solinger R, Elbl F, Minhas K. Echocardiography in the normal neonate. Circulation 1973; 47: 108-18.

4 Epstein ML, Goldberg SJ, Allen HD, Konecke L, Wood J. Great vessel, cardiac chamber, and wall growth patterns in normal children. Circulation 1975; 51: 1124-9.

5 Weyman AE, Caldwell RL, Hurwitz RA, et al. Crosssectional echocardiographic characterization of aortic obstruction: 1. Supravalvular aortic stenosis and aortic hypoplasia. Circulation 1978; 57: 491-7.

6 Becker AE, Tynan MJ, Anderson RH. Cardiac anatomy in congenital heart disease. In: Bom $\mathrm{N}$, ed.
Echocardiology. The Hague: Martinus Nijhoff, 1977: 11322.

7 Ligtvoet CM, Ridder J, Lancée CT, Hagemeijer F, Vletter WB, Gussenhoven WJ. A dynamically focused multiscan system. In: Bom N, ed. Echocardiology. The Hague: Martinus Nijhoff, 1977: 313-23.

8 Armitage P. Statistical methods in medical research. 1st ed. Oxford: Blackwell Scientific Publications, 1971.

9 Van Meurs-van Woezik H. The great arteries in normal and some congenitally malformed hearts, their internal calibres and tunica media in relation to blood flow. Rotterdam, The Netherlands, 1979. Thesis.

10 Van Meurs-van Woezik H, Klein HW. Calibres of aorta and pulmonary artery in hypoplastic left and right heart syndromes: effects of abnormal bloodflow? Virchows Arch [Pathol Anat] 1974; 364: 357-64.

11 Goldberg SJ, Allen HD, Sahn DJ. Pediatric and adolescent electrocardiology. London: Year Book Medical Publishers, 1975: 43-5.

12 Allen HD, Lange LW, Sahn DJ, Goldberg SJ. Ultrasound cardiac diagnosis. Pediatr Clin North Am 1978; 25: 677-706.

13 Van Meurs-van Woezik H, Krediet P. Measurements of the descending aorta in infants and children: comparison with other aortic dimensions. F Anat 1982 135: 273-9.

Requests for reprints to Dr W J Gussenhoven, Laboratory for Experimental Echocardiography, Erasmus Universiteit, Ee 2302, PO Box 1738, 3000 DR Rotterdam, The Netherlands. 